\title{
Infantile Perineal Protrusion in Two Monochorionic Twins
}

\author{
Paola Cavicchioli, MD ${ }^{1}$ Enrico Valerio, MD ${ }^{2}$ Mario Cutrone, MD \\ 1 Department of Pediatrics, Ospedale Dell'Angelo, Mestre, Venice, Italy \\ ${ }^{2}$ Department of Woman and Child Health, Medical School, University \\ of Padova, Padova, Italy \\ Address for correspondence Enrico Valerio, MD, Department of \\ Woman and Child Health, Medical School, University of Padova, Via \\ Giustiniani, 335128 Padova, Italy \\ Am J Perinatol Rep 2014;4:e81-e82. \\ (e-mail: enrico.valerio.md@gmail.com; enrico.va@inwind.it).
}

\begin{abstract}
Keywords

- infantile perineal protrusion

- monochorionic twins

- congenital disease

- neonatology

Case Report Two female monochorionic-monoamniotic twins showed the same kind of infantile perineal protrusion (IPP) at birth. Lesions in both twins progressively healed until resolution in 6 weeks' time; none of the twins have manifested, till date, alvus disturbances. Discussion and Literature Review A literature review numbers approximately 100 reports of IPP. This condition has been classically classified into three categories: congenital/familiar (i.e., female sex, positive parental history of IPP), acquired (mainly due to constipation), and associated with lichen sclerosus et atrophicus.

Conclusions and Final Remarks This case report describes, for the first time, the presence of IPP in monochorionic-monoamniotic twins, supporting the existence of hereditary/genetic factors in the developing of this condition.
\end{abstract}

\section{Case Report}

Two female monochorionic-monoamniotic twins were born from cesarean section at $37^{+2}$ weeks. Pregnancy was regular, and fetal echographies have been always normal. Maternal serologies were negative. At first clinical evaluation 3 hours after birth the same pinkish, rubbery, stem-like perianal lesion was noted in both the twins (-Fig. 1), consistent with infantile perineal protrusion (IPP). First-born twin (on the left in the picture) presented with IPP on the left border of the anal orifice, while second-born twin (on the right in the picture) presented with median-line IPP anterior to the anus.

A literature review numbers approximately 100 reports of IPP, ${ }^{1,2}$ with a striking predominance of female sex. IPP, also called infantile perianal pyramidal protrusion due to its shape, ${ }^{3}$ has been classically classified into three categories: constitutional (sometimes familial and/or congenital), acquired, and linked to lichen sclerosus et atrophicus (LSA). ${ }^{4}$

Constitutional IPP is thought to be originated either from a weakness in the perineal area of females ${ }^{4}$ or from the remnants of urogenital septum tip ${ }^{1}$; only the first theory could account for the marked prevalence of the female sex for this condition. Till date, no convincing explanation for the presence of constitutional IPP in males too has been produced. ${ }^{5} \mathrm{~A}$ considerable amount of lesions in this group has been diagnosed at birth (i.e., congenital), and in some cases a parental history of IPP was detectable (i.e., familial). ${ }^{6}$

No previous reports describe IPP in monochorionic twins.

Acquired IPP is thought to be related to constipation in older children; while evidence exists of regression of IPP after effective management of constipation, ${ }^{7}$ it is still not clear whether constipation causes IPP or, vice versa, constipation is a consequence of the development of the IPP. ${ }^{4,5}$ Some Authors linked acquired IPP to perineal mechanical stimulation due to wiping after defecation. ${ }^{3}$ Also, the presence of chronic diarrhea and/or fistulas may also contribute to acquired IPP by means of a chronic mechanical stimulation of the perineum. ${ }^{2}$

Finally, IPP has been related to LSA, either as an early, telltale sign or as a coexisting manifestation of the disease. ${ }^{2}$ Some Authors suggested that IPP itself may represent a peculiar variation of LSA. ${ }^{8}$ received

April 21, 2014

accepted after revision

May 27, 2014

published online

August 11, 2014
DOI http://dx.doi.org/

10.1055/s-0034-1383853. ISSN 2157-6998.
Copyright $\odot 2014$ by Thieme Medical Publishers, Inc., 333 Seventh Avenue, New York, NY 10001, USA. Tel: +1(212) 584-4662.
License terms

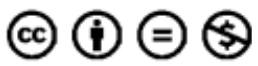




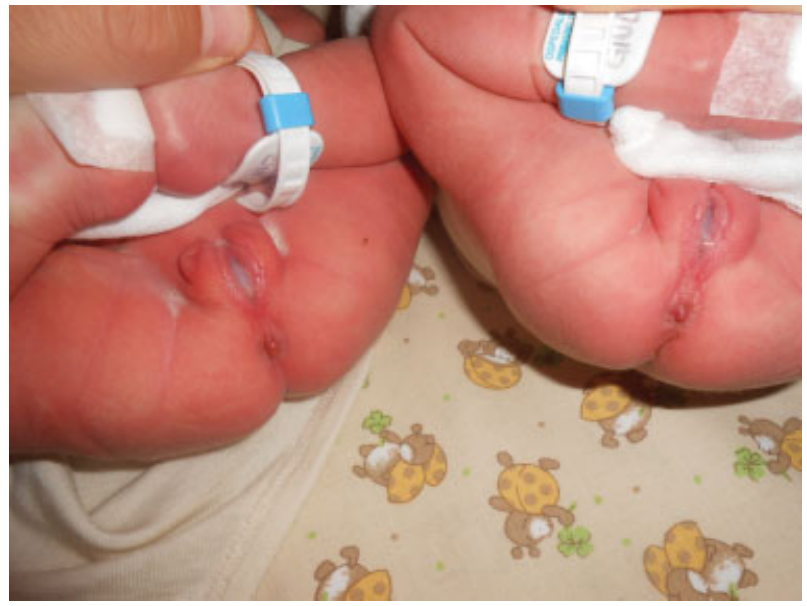

Fig. 1 Infantile perineal protrusion in two female monochorionicmonoamniotic twins at birth.

Differential diagnoses of IPP encompass sexual abuse, perianal Crohn disease, hemorrhoid disease, rectal prolapse, and hemangiomas. ${ }^{1,3,5,9}$

Constitutional IPP most often resolves in a few weeks' time from initial diagnosis, thus warranting a conservative approach $^{3}$; less frequently, this form of IPP may persist over several years. ${ }^{2,4}$

Acquired IPP may regress upon effective treatment of constipation $^{6,7}$ or, more rarely, may persist despite alvus normalization. ${ }^{2}$

LSA-related IPP treatment may encompass topical steroid therapy, ${ }^{10}$ although spontaneous resolution of the IPP has been documented also in this condition. ${ }^{8}$

Consistently with constitutional IPP, lesions in both presented twins progressively healed until resolution in 6 weeks' time; none of the twins have manifested, to date, alvus disturbances.
This report is of educational value since it contains the first observation of congenital IPP in two monochorionic-monoamniotic female twins at birth: such evidence supports the existence of hereditary/genetic factors in the development of the IPP.

\section{Conflict of Interest \\ None.}

\section{References}

1 Konta R, Hashimoto I, Takahashi M, Tamai K. Infantile perineal protrusion: a statistical, clinical, and histopathologic study. Dermatology 2000;201(4):316-320

2 Patrizi A, Raone B, Neri I, D’Antuono A. Infantile perianal protrusion: 13 new cases. Pediatr Dermatol 2002;19(1):15-18

3 Kayashima K, Kitoh M, Ono T. Infantile perianal pyramidal protrusion. Arch Dermatol 1996;132(12):1481-1484

4 Zavras N, Christianakis E, Tsamoudaki S, Velaoras K. Infantile perianal pyramidal protrusion: a report of 8 new cases and a review of the literature. Case Rep Dermatol 2012;4(3): 202-206

5 Fleet SL, Davis LS. Infantile perianal pyramidal protrusion: report of a case and review of the literature. Pediatr Dermatol 2005;22(2): 151-152

6 Leung AK. Concomitant anterior and posterior infantile perianal protrusions. J Natl Med Assoc 2010;102(2):135-136

7 Mérigou D, Labrèze C, Lamireau T, Vergnes P, Taïeb A. Infantile perianal pyramidal protrusion: a marker of constipation? Pediatr Dermatol 1998;15(2):143-144

8 Cruces MJ, De La Torre C, Losada A, Ocampo C, García-Doval I. Infantile pyramidal protrusion as a manifestation of lichen sclerosus et atrophicus. Arch Dermatol 1998;134(9):1118-1120

9 Tsunemi Y, Matsushita T, Takahashi T, Tamaki T. Childhood capillary hemangioma presenting as infantile perianal protrusion. Dermatology 2003;207(4):408-409

10 Kim BJ, Woo SM, Li K, Lee DH, Cho S. Infantile perianal pyramidal protrusion treated by topical steroid application. J Eur Acad Dermatol Venereol 2007;21(2):263-264 